\title{
An Exploratory, Preliminary Report on United States Weather Education Trends and General Population Links Between Weather Salience and Systemizing
}

\author{
MATTHEW J. BOLTON \\ College of Arts and Sciences, Saint Leo University, Saint Leo, FL \\ and How The Weatherworks, Naples, FL \\ H. MICHAEL MOGIL \\ How The Weatherworks, Naples, FL \\ LARA K. AULT \\ College of Arts and Sciences, Saint Leo University, Saint Leo, FL
}

(Manuscript received 7 February 2019; review completed 23 October 2019)

\begin{abstract}
Meteorologists have been interested in STEM (science, technology, engineering, and math) education endeavors for many years. The present study's authors recently observed an apparent trend in United States public schools away from weather content in physical science classes, especially at higher grade levels. Through the blending of multiple psychological theories, this study sought to examine when people in the United States are presented with educational weather content at the Kindergarten to Grade 12 (K-12) levels and also investigated links between two psychological constructs: Weather salience and systemizing. Recent evidence among people on the autism spectrum suggests that weather salience-psychological attention to weather-is linked to systemizing, a psychological process that involves attention-to-detail and pattern recognition, thus prompting an investigation of this relationship in the general population. Results preliminarily suggest that K-12 weather education in the United States occurs most often in the elementary and middle school years, but that people receiving weather education only in high school, and intriguingly a combination of elementary and high school, but not middle school, have the highest weather salience levels. There was also a positive relationship between weather salience and systemizing. Results are discussed in light of the weather salience, systemizing, and social cognitive career theories.
\end{abstract}

\section{Introduction}

Meteorologists long have been involved in STEM (science, technology, education, and math) education efforts. Previous research at the intersection of meteorology and education has investigated topics at the grade school (Stewart et al. 2015, 2018, related to the involvement of teachers in weather education) and undergraduate (Knox and Ackerman 2005; Knox 2008; Mass 1996; and Vali and Anthes, 2003, related to student enrollment) levels. The United States National Weather Service (NWS), both the National Weather Association
(NWA) and American Meteorological Society (AMS), and many private sector and broadcast meteorology entities have put substantial effort into educating people in the United States about weather.

The first and second authors have observed and taken part in many of these efforts while working the weather, science, math, and other education arenas as members of the private and academic sectors. One recent observation is the seeming trend in United States public schools for a shift away from weather content in physical science classes, especially at the middle and high school grade levels. The study presented here thus

Corresponding author address: Matthew J. Bolton, State Road 52, Saint Leo, FL, 33574 
sought to examine when people in the United States learn about weather in K-12. Even though our primary hypothesis revolved around that question, and was interpreted with social cognitive career theory, we were also curious about the intersection of two psychological theories, weather salience (psychological attention to weather) and systemizing (which involves attention to detail). These three theoretical views are discussed next.

\section{a. Social cognitive career theory}

Social cognitive career theory, based on general social cognitive theory Bandura (1986), is often used to explain the learner-environment-behavior relationship underscoring academic and career choices (Lent and Brown 2006; Wang 2013). Of interest to us is that it has been used as an explanatory model for entrance into STEM fields (e.g., Betz and Hackett 1983; ByarsWinston et al. 2010; Hackett et al. 1992; Lent et al. 1993; Lent et al. 2008; Wang 2013). Wang (2013) argued that intent to enter into STEM fields is a result of motivational factors, and also high school seniors' achievement level in math, exposure to math and science courses, and math self-efficacy beliefs (the students' confidence in their own mathematical abilities).

\section{b. Weather salience}

Stewart (2009) broadly defined weather salience as the level of psychological attention people pay to weather phenomena. Weather salience involves perceptual salience (the extent to which people notice things; Taylor and Fiske 1978); valence (Barrrett 1998; specifically, here, the extent to which weather events induce an emotional response); duration and periodicity (the significance of weather based on its variability and predictability; Evans and Cohen 1987); and psychological and emotional attachment (see Knez 2005, and Morgan 2010, for discussion of place attachment). Epistemic (i.e., informational) curiosity (Litman and Spielberger 2003) and knowledge are other important components of weather salience.

\section{c. Systemizing}

The systemizing concept comprises half of the empathizing-systemizing (E-S) theory put forth to explain aspects of autism spectrum condition (ASC), and as a cognitive style model through which to view psychological sex and gender differences between men and women. Cognitive styles are frameworks for the way people think, gather, process, use, and remember information (Kozhevnikov 2007). E-S theory (see e.g., Baron-Cohen et al. 2003; Wheelwright et al. 2006; Kidron et al. 2018; Svedholm-Häkkinen et al. 2016) deals specifically with autism's social and non-social features, attributing the social difficulties characteristic of the condition to weaknesses in cognitive empathizing - the ability and drive to imagine another person's mental states (i.e., their thoughts, intentions, desires, feelings) - and the autistic tendency for detailorientation to strengths in systemizing. It further predicts that women will be stronger empathizers than men, who are said to possess a cognitive style rooted in systemizing. Women, on average, show higher levels of empathy, whereas systemizing tends to be stronger among men (e.g., Baron-Cohen et al. 1986, 2001, 2003; Lawson et al. 2004; Wheelwright et al. 2006).

Systemizing is theorized as the drive and ability to identify and formulate psychological systems, which are sets of logical rules one uses to explain the workings of the physical world. Systems follow predictable patterns - starting with an input that leads to an operation and culminates with a reliable output (hence, any information that functions in a lawful, ifthen manner can be systemized; other information is more difficult to systemize due to its variance and unpredictability). Some people are stronger in empathizing, some in systemizing - and some have a more balanced cognitive profile (Baron-Cohen 2003). Systemizing drives the brain to predict certainty through the observation of individual details (variables) in systems, and subsequent monitoring of the overall system for lawful change after of the individual variable (Baron-Cohen 2003).

Because systemizing is concerned with the psychological analysis of logical rules and patterns, we have been curious about and previously investigated its linkages to weather salience in autistic people, who are naturally strong systemizers (see Bolton et al. 2018 for in-depth discussion). The present study builds on that work, investigating possible links between systemizing and weather salience in the general population. We predicted these would be positively correlated. 


\section{Data and method}

\section{a. Participants}

Table 1 shows participant demographics. Participants ( $\mathrm{N}=280$ filtered to 251) were recruited primarily through posts at the Global Weather and Climate Center (GWCC) blogsite (globalweatherclimatecenter.com) and to a much lesser extent on social media (Facebook, Reddit, and Twitter; participant origin data are not available but will be addressed in future work).

\section{b. Procedure}

Participants first responded to demographic items pertaining to age, gender, race, and United States state of residence, and then asked to respond to individual difference measures - the Systemizing Quotient-Revised (SQ-R; Wheelwright et al. 2006) and the Weather Salience Questionnaire (WxSQ; A. Stewart, 2009) - in an online, Qualtrics-hosted survey. Participants also were asked whether or not, and when, they had received weather education in K-12.

The 75-item SQ-R measures interest in, or preference for, different kinds of systems. Two points are scored for strong endorsement of the systemizingoriented response, and one point is scored for slight endorsement. An example item is "When I have a lot of shopping to do, I like to plan which shops I am going to visit, and in what order." The 29-item WxSQ

measures the multiple dimensions of weather salience across the seven scale factors of attention to weather, weather sensing and direct observation of weather, effects of weather on daily activities, attachment to weather patterns, effects of weather on mood, need for weather variability, and attention to weather-induced holidays. Example items include "I take notice of how the air outside sometimes smells differently after it rains," and "I seek out more up-to-date weather information than what is provided on the television or radio." Cronbach's $\alpha$, a statistical tool (Cronbach 1951) used by psychologists to determine scale reliability, was calculated for both measures. Alpha scores (SQ-R: 0.94; WxSQ: 0.78), ranging from 0-1, measure the degree to which items are intercorrelated, with a standard of acceptable reliability starting at 0.70 .

\section{c. Data analysis plan}

As proponents of scientific transparency, we wish to disclose not only that the data reported here were collected as part of a larger study into ways people visualize and subsequently estimate falling rain, but that we were invited to publish preliminary, AMSAnnual-Meeting-presented results in the AMS Bulletin (Bolton et al. 2018). While at that time we indicated full publication was imminent, we are presenting here the data we feel is ethical to report given concerns of publishing misconduct when reusing subsets of samesample data (e.g., Marcus and Oransky 2012; Wager et al 2009). ${ }^{1}$ We do not want to unduly influence the evidence base for these findings. Those wishing to view our data in full and draw their own conclusions may do so at: osf.io/sf8rd.

The initial dataset $(\mathrm{N}=280)$ was filtered such that only participants who provided their age, gender, racial classification, and state of residence were included. We further excluded nonbinary respondents, as these were not of sufficient number for fair statistical comparison with the recruited men and women. We also removed from the dataset any outlying scores (on the WxSQ and SQ-R) that were +/- 2 standard deviations (SD) from the mean. The resulting final sample size was $\mathrm{N}=251$.

Cross-group sample size insufficiencies prevented statistical analysis of the weather education data (e.g., with a chi-square test, to test for differences in education level frequencies; or to test means via analysis of variance, ANOVA). Thus, reported first are the education group means for weather salience, followed by the results of a Welch's ANOVA for our statistical comparison of gender differences in weather salience and systemizing. As part of this test, we computed etasquared $\left(\eta^{2}\right)$ effect sizes, 95\% Bonferroni-corrected confidence intervals (CI), and statistical power. Effect sizes range from $0-1$ and measure the standardized difference between means (Levine and Hullett 2002), whereas CIs estimate the range between which the value of the particular variable being assessed could

\footnotetext{
${ }^{1}$ We therefore report final analyses related to weather salience and systemizing, and weather education, but not rainfall perceptions. We used a different method for the Bulletin analyses - not only a different statistical method (analysis of covariance) but a different systemizing variable, representing the construct as we then understood it. The descriptive rainfall perception percentages also did not change much with new participants, post-conference, so that data seemed unethical to report here with only tiny differences.
} 
Table 1. Breakdown of participant $(\mathrm{N}=251)$ racial, gender, age, geographic, and weather education distributions.

\begin{tabular}{|c|c|c|c|c|c|}
\hline \multicolumn{6}{|c|}{ Racial Classification } \\
\hline $\begin{array}{l}\text { European- } \\
\text { American }\end{array}$ & $\begin{array}{l}\text { African- } \\
\text { American }\end{array}$ & Asian & Latino/a & Hispanic & Other \\
\hline $228(90.8 \%)$ & 5 & 4 & 3 & 2 & 8 \\
\hline
\end{tabular}

\begin{tabular}{|c|c|c|c|c|}
\hline \multicolumn{5}{|c|}{ Gender and Age } \\
\hline Women & Men & Mean & SD & Range \\
\hline $141(56.2 \%)$ & 110 & 40.03 & 15.47 & $18-79$ \\
\hline
\end{tabular}

\begin{tabular}{|c|c|c|c|c|}
\hline \multicolumn{5}{|c|}{ Participant Location } \\
\hline Southeast & Central & Northeast & Southwest & Northwest \\
\hline $144(57.4 \%)$ & 46 & 38 & 12 & 11 \\
\hline
\end{tabular}

\begin{tabular}{|c|c|c|c|c|c|c|}
\hline \multicolumn{7}{|c|}{ Categorical Weather Education Level (of $\mathbf{n}=178)$} \\
\hline Elementary & Middle & High & Elementary & Elementary & Middle & All Grades \\
41 & 11 & 13 & and Middle & and High & and High & 66 \\
$(16.3)$ & $(4.4 \%)$ & $(5.2 \%)$ & $31(12.4 \%)$ & $7(2.8 \%)$ & $9(3.6 \%)$ & $(26.3 \%)$ \\
\hline
\end{tabular}

be expected to fall if a study were conducted multiple times with the same sample size drawn from the same population (Boslaugh 2012). Power, also ranging from $0-1$, represents the likelihood of correctly detecting a true statistical effect in the data (Boslaugh 2012). In closing, we report correlational analyses for the relationships between weather salience and systemizing.

\section{Results}

\section{a. Weather education data}

Analysis of the weather salience means for each education group (Table 2) revealed interesting trends as to who specifically had the highest weather salience. Participants who learned about weather only in elementary school were lowest of any single group in weather salience. Weather salience increased slightly for participants who only learned about weather in middle school, and then again for participants who only learned in high school. Participants who learned about weather in both elementary and middle school were lowest in combined-group salience, whereas those who learned in both middle and high school scored slightly higher. Intriguingly, participants who reported learning about weather in elementary and high, but not middle, school, had the highest weather salience scores.

\section{b. Systemizing and weather salience differences}

Welch's ANOVA uncovered significant gender differences in both SQ-R and WxSQ scores, with Tables 3 and 4 showcasing that men were both more expressive of systemizing and more weather salient than the recruited women. Systemizing was positively and significantly correlated with weather salience, $\mathrm{r}(143)=0.39, \mathrm{p}<0.001$, confirming our prediction of a positive relationship between the two constructs in the general population.

\section{Discussion}

Using a blend of psychological theories and with implications for both pre-college and university meteorology education efforts, this study provides a preliminary but important look at K-12 weather education trends in the United States. Participants who learned about weather in high school alone were more weather salient than those who learned in elementary or middle school alone, and those who learned in both elementary and high school, but not middle school, were even more weather salient than the high school learners.

Too few participants received weather education in elementary and high school to allow reliable conclusions, but it is nonetheless intriguing that those participants reported the greatest weather salience (see Table 2 for group means). Though available data cannot test theory hypotheses further, this can perhaps 
Table 2. Weather Salience Across Grade Levels. Highest values for single and mixed groups are bolded. Elementaryonly $n=33$; Middle-only $n=9$; High-only $n=11$; Elementary and middle $n=24$; Middle and high $n=8$; Elementary and high $n=5$; All levels $n=55$.

\begin{tabular}{|c|c|c|c|c|c|c|c|c|}
\hline \multicolumn{2}{|c|}{ Weather Salience Across Grade Levels } \\
\hline \multicolumn{2}{|c|}{ Group } & $\begin{array}{c}\text { Elemtary } \\
\text { School }\end{array}$ & $\begin{array}{c}\text { Middle } \\
\text { School }\end{array}$ & $\begin{array}{c}\text { High } \\
\text { School }\end{array}$ & $\begin{array}{c}\text { Elementary } \\
\text { and Middle }\end{array}$ & $\begin{array}{c}\text { Middle } \\
\text { and High }\end{array}$ & $\begin{array}{c}\text { Elementary } \\
\text { and High }\end{array}$ & $\begin{array}{c}\text { All Grade } \\
\text { Levels }\end{array}$ \\
\hline Weather & $(\mathrm{M})$ & 110.85 & 111.89 & $\mathbf{1 1 7 . 0 9}$ & 109.08 & 111.25 & $\mathbf{1 1 9 . 0 0}$ & 115.67 \\
Salience & $(\mathrm{SD})$ & $(11.85)$ & $(9.56)$ & $(8.75)$ & $(13.00)$ & $(9.6)$ & $(1.58)$ & $(12.22)$ \\
\hline
\end{tabular}

be explained by social cognitive career theory, which suggests high school exposure to math and science topics as one reliable predictor of STEM interest. Early and later weather education experiences might serve as a kind of combined outcome primacy (Shteingart et al. 2013), and recency effect (Bjork and Whitten 1974) such that the seed of interest in and importance of weather is planted in elementary school and influences future class topic choices. Then, interest is reinvigorated and wellremembered when weather is one of the final topics students learn later (in high school). The observed earlylate education combination may reflect few middle school opportunities for weather education at those grade levels, or disinterest due to a lack of adequate exposure to weather concepts. However, current data do not allow us to make inferences for this speculation. These two factors have been common to us as weather educators, and further corroborated by meteorologiststurned-school-teachers with whom we talked (personal communication, D. Faysash, B. Schuerman, 2018). As it is unclear whether lack of exposure or lack of interest guide these educational experiences, future research should examine student interest, broadly, across grade levels.

Data provided further evidence for the hypothesized link between systemizing and weather salience (Bolton et al. 2018b). Although our effect sizes were small, we had enough statistical power to detect the gender differences in both variables. Given suggestions (e.g., Hyde 2014, Ritchie et al. 2018) that psychological differences in men are more variable than in women, systemizing-driven weather salience differences may be small and context-specific. The men recruited for this study were significantly more weather salient, and also more expressive of systemizing, than the recruited women. This finding is counter to the established representative population weather salience differences in men and women (i.e., women in the general United States population tend to be more expressive; see A. Stewart 2009 and A. Stewart et al. 2012), which are supported by other research nationally, and internationally, with data from the Pew Research Center, Australian Bureau of Meteorology (BoM), and U.K. Met Office. ${ }^{2}$ However, this finding lends credence to research on weather salience in autistic people and neurotypical men (see osf.io/xzn7a/ for unpublished gender data from Bolton et al. 2018b; Excel versions of the original SPSS files are available; the .QDP files can be read with the QDA Miner Lite software available at https://provalisresearch.com/products/qualitative-dataanalysis-software/freeware/) and other neurotypical population work also suggestive of systemizing enhancement of weather salience. ${ }^{3}$

In closing, we aim to establish a profile by which meteorologists and other weather educators could potentially identify young students intent on entry into the meteorological field. First, given physical scientists disposition for introversion and independence (Bachtold 1976; Eiduson 1962; Feist 1998; Roe 1952; Wilson \& Jackson 1994), and lower threshold for social arousal (Eysenck 1997) it might be expected these

2 The Pew Research Center (2008) observed women paid more attention to weather-related news than men; the BoM (Maddern and Jenner 2009) found Australian women use weather information more often than men; and the U. K. Met Office (2015) reported that women in the U.K. talk about weather $68 \%$ of the time, more often than any other topic. Also see Geddes' 2015 BBC News article for perspective on this topic.

${ }^{3}$ One study (Williams et al. 2017) sampled participants from two weather blogs and observed men to be higher in weather salience than their recruited women. The BoM (2009) found women more attentive to weather information, but that men checked more often via the BoM website (suggesting the use of / interest in technology as a source of information is increasing the systemizing and, in turn, weather salience, response). Still other researchers (Phan et al. 2018) have observed men to find more importance in the technical aspects of weather forecast information (radar and satellite) presented within smartphone weather applications. 
Table 3. Welch's ANOVA differences in SQ-R scores for men and women. Data shown are group means, $S D$ (in parentheses), CI [in braces], and ANOVA statistics: Between- and within- groups, and total, degrees of freedom, sums of squares, mean squares, $F$ statistic, $p$ value, eta-squared, and power.

\begin{tabular}{|c|c|c|c|c|c|c|c|c|c|}
\hline$M_{\text {Men }}$ & $M_{\text {Women }}$ & Source & $d f$ & SS & MS & $F$ & $p$ & $\eta^{2}$ & Power \\
\hline 71.17 & 61.06 & $\begin{array}{c}\text { Between } \\
\text { groups }\end{array}$ & 1 & 3974.64 & 3794.64 & 10.27 & 0.002 & 0.07 & 0.91 \\
$(21.00)$ & $(16.35)$ & & & & & & \\
\hline$[65.89$, & {$[57.63$,} & $\begin{array}{c}\text { Within } \\
\text { groups }\end{array}$ & 111.77 & 51145.80 & 338.714 & \multicolumn{3}{|l}{} \\
$76.46]$ & $64.48]$ & & & & &
\end{tabular}

Table 4. Welch's ANOVA differences in WxSQ scores for men and women. Data shown are group means, $S D$ (in parentheses), $C I$ [in braces], and ANOVA statistics: Between- and within- groups, and total, degrees of freedom, sums of squares, mean squares, $F$ statistic, $p$ value, eta-squared, and power.

\begin{tabular}{|c|c|c|c|c|c|c|c|c|c|}
\hline$M_{\text {Men }}$ & $M_{\text {Women }}$ & Source & $d f$ & SS & MS & $F$ & $p$ & $\eta^{2}$ & Power \\
\hline $\begin{array}{c}114.89 \\
(11.67)\end{array}$ & $\begin{array}{c}110.97 \\
(11.62)\end{array}$ & $\begin{array}{c}\text { Between } \\
\text { groups }\end{array}$ & 1 & 748.837 & 748.837 & 5.52 & 0.02 & 0.05 & 0.79 \\
\hline $\begin{aligned} {[112.36,} \\
117.43]\end{aligned}$ & $\begin{array}{c}{[108.82,} \\
113.11]\end{array}$ & $\begin{array}{c}\text { Within } \\
\text { groups }\end{array}$ & 178.52 & 26687.897 & 135.472 & \multicolumn{2}{|l}{} \\
\hline
\end{tabular}

students will be more socially aloof and disinterested and, perhaps accordingly, to have a greater need for cognition (NFC; i.e., the tendency to engage in and enjoy effortful thinking; Feist 2012) as they tend to be more introspective. Interestingly, research (e.g., Baron-Cohen et al. 2001, 2007; Bolton et al. 2018a) has found physical scientists, including meteorologists, high in traits characteristic of autism, and one marker of autism is social disinterest (Clements et al. 2018). However, meteorologists who gravitate towards weather broadcasting are much more extroverted (Bolton and Ault 2019), sharing this trait with social scientists (Feist 2006). This is in line with the hybrid cognitive profile hypothesis (Baron-Cohen 2003) and results in support of this, indicating meteorologists are strong in empathizing as well as systemizing (Bolton et al. 2018a).

Second, and on a related note, these individuals will likely be strong in systemizing with a correspondingly higher interest for things than for people (Feist 2006; Graziano et al. 2011; Prediger 1982). Baron-Cohen and colleagues (1997, 1998, 2001, 2007, 2009; BaronCohen 2015; Billington et al. 2007; Wheelwright et al. 2006) and other researchers (e.g., M. Stewart and Austin 2009; Zeyer et al. 2012) have linked systemizing to a predisposition for STEM interest. Meteorologists previously have been found to be good systemizers (Bolton et al. 2018a), while recent research into psychological factors associated with learning and practicing meteorology (McNeal et al. 2019) revealed that cognitive disembedding ability (observing and recognizing patterns among a mass of nonessential information) positively predicts meteorological data analysis skill. One component of systemizing, attention to detail, can be tested by assessing cognitive disembedding. Billington et al. (2007) found physical scientists perform well on this metric-another predictor of STEM field entry.

Third, one might expect weather-interested students to display higher levels of trait conscientiousness, and thus to have a higher regard for duty and commitment; and to be more dispositionally open to new experiences. Our work with meteorologists (Bolton et al. 2018a; Bolton and Ault 2019) has found them highly conscientious, agreeable, and extraverted (regarding this and empathy, they seem to present a hybrid cognitive profile among physical scientists). Feist (2012) found openness and NFC positively correlated with one another and that introversion is likewise linked with science interest. Nettle (2007) suggests, meanwhile, that systemizing also is related to openness and conscientiousness. In sum, then, from this pattern of results we can build a simple heuristic profile of weather-interested students: That they are more introverted and open, likelier to think deeply and problem-solve-by-reflection, and that they are more conscientious (befitting their detailorientation).

\section{Conclusions, limitations, and future work}

This exploratory study produced preliminary evidence that weather salience is related to the amount of 
weather-related education $\mathrm{K}-12$ students receive as well as when they receive it. We also further confirmed the positive relationship between systemizing and weather salience, and replicated an interesting gender difference in weather salience, which observed data suggests might be moderated by systemizing. These findings could be important to informing future meteorological education efforts not only at the university level but, crucially, at the developmentally formative pre-college level.

The small sample size, foremost among this study's limitations, considerably affected our statistical analyses and subsequent inferential power. Further, the results are not widely generalizable because our recruiting strategy - sampling readers of a weather blog and from among the lead and second authors' social networks, where many people are either meteorologists themselves or exposed more to weather contentpresents a possible selection bias that could skew the results towards a higher attunement for weather. We also cannot know for sure how many participants came from social media or the GWCC blog. Future research should rectify these limitations and attempt replication of this study's results in a larger, more generalizable sample.

Acknowledgments: All authors contributed to the study design. MJB and LKA analyzed the data. MJB was the primary manuscript author with support from HMM and LKA (all approved the final draft). We are grateful to Jordan Rabinowitz for allowing our survey to be distributed via his GWCC website; to the survey participants; and to Garrett Harvey for his assistance in the larger study of which this work was a part. This study was conducted without funding, although MJB was supported academically by a Graduate Fellowship sponsored by the National Weather Service and awarded by the American Meteorological Society. The opinions, conclusions, and recommendations expressed here are those of the authors and do not necessarily reflect the views of the American Meteorological Society or National Weather Service. We have no conflicts of interest to declare. We are grateful to JOM Associate Editor Dr. Ariel Cohen and three anonymous reviewers whose kind and thorough comments greatly strengthened the final paper.

\section{REFERENCES}

Australian Bureau of Meteorology, 2009: Public User Survey - 2009. A Report of Research Findings. 8 pp. [Available online at: wmo.int/pages/prog/amp/pwsp/documents/ Public User_Survey Report Summer09 Australia.pdf]

Bachtold, L. M., 1976: Personality characteristics of women of distinction. Psychol. Women Quart., 1, 70-78. CrossRef.

Bandura, A., 1986: Social Foundations of Thought and Action: A Social Cognitive Theory. Prentice Hall. $617 \mathrm{pp}$.

Barrett, L. F., 1998: Discrete emotions or dimensions? The role of valence focus and arousal focus. Cognition and Emotion, 12 (4), 579-599. CrossRef.

Baron-Cohen, S., A. M. Leslie, and U. Frith, 1986: Mechanical, behavioral and intentional understanding of picture stories in autism children. Brit. J. Dev. Psychol., 4, 113-125. [Available online at: docs. autismresearchcentre.com/papers/1986_BC_etal PictureStoriesInASChildren.pdf]

, S. Wheelwright, C. Stott, P. Bolton, and I. Goodyer, 1997: Is there a link between engineering and autism? Autism, 1, 101-109. CrossRef.

, P. Bolton, S. Wheelwright, V. Scahill, L. Short, G. Mead, and A. Smith, 1998: Does autism occur more often in families of physicists, engineers, and mathematicians? Autism, 2, 296-301. CrossRef.

, S. Wheelwright, R. Skinner, J. Martin, and E. Clubley, 2001: The autism-spectrum quotient (AQ): evidence from Asperger Syndrome/high-functioning autism, males and females, scientists and mathematicians. $J$. Autism Dev. Disord., 31, 5-17. CrossRef.

, S. Wheelwright, V. Scahill, A. Spong, and J. Lawson, 2001: Studies of theory of mind: Are intuitive physics and intuitive psychology independent? J. Dev. Learn. Disord., 5, 47-78. [Available online at: docs. autismresearchcentre. com/papers/2001 BCetal kidseyes.pdf].

2003: The essential difference: Men, women and the extreme male brain. Penguin/Basic Books. 288 pp.

J. Richler, D. Bisarya, N. Gurunathan, and S. Wheelwright, 2003: The Systemizing Quotient: An investigation of adults with Asperger Syndrome or high-functioning autism, and normal sex differences. Philos. Trans. R. Soc. Lond. B, 358, 361-374. CrossRef. , S. Wheelwright, A. Burtenshaw, and E. Hobson, 2007: Mathematical talent is linked to autism. Hum. Nat., 18, 125-131. CrossRef.

, E. Ashwin, C. Ashwin, T. Tavassoli, and B. Chakrabarti, 2009: Talent in autism: Hyper-systemizing, hyperattention to detail and sensory hypersensitivity. Philos. Trans. R. Soc. Lond. B Biol. Sci., 364, 1377-1383. CrossRef.

, 2015: Autism, maths, and sex: The special triangle.

The Lancet Psychiatry, 2, 790-791. CrossRef. 
Betz, N. E., G. Hackett, 1983: The relationship of mathematics self-efficacy expectations to the selection of science-based college majors. J. Vocational Behav., 23 (3), 329-345. CrossRef.

Billington, J., S. Baron-Cohen, and S. Wheelwright, 2007: Cognitive style predicts entry into physical sciences and humanities: Questionnaire and performance tests of empathy and systemizing. Learn. Ind. Differ., 17 (3), 260-268. CrossRef.

Bjork, R. A. and W. B. Whitten, 1974: Recency-sensitive retrieval processes in long-term free recall. Cog. Psychol., 6 (2), 173-189. CrossRef.

Bolton, M. J. L. K. Ault, D. M. Greenberg, and S. BaronCohen, 2018a: Exploring the human side of meteorology: A brief report on the psychology of meteorologists. $J$. Oper. Met., 6, 23-32. CrossRef.

, W. G. Blumberg, H. M. Mogil, L. K. Ault, and S. H. Hanes, 2018b: Initial evidence for increased weather salience in autism spectrum conditions. Preprint at PsyArxiv. 49 pp. CrossRef.

, Mogil, H. M., G. T. Harvey, and L. K. Ault, 2018c: Rainfall estimation skill and links between weather salience and detail orientation. Bull. Amer. Met. Soc., 99 (11), 2226-2227.

, and L. K. Ault, (2019). Weathering the storms of nature and life: workplace wellbeing and mental health in meteorologists of the United States. Preprint at PsyArxiv. 29 pp. CrossRef.

Boslaugh, S., 2012: Statistics in a nutshell: A desktop quick reference (second edition). O'Reilly Media Inc., 594 pp.

Byars-Winston, A. M., Y. Estrada, C. Howard, D. Davis, and J. Zalapa, 2010: Influence of social cognitive and ethnic variables on academic goals of underrepresented students in science and engineering: a multiple-groups analysis. J. Counseling Psychol., 57, 205-218. CrossRef.

Campbell, J. M., 1983: Ambient stressors. Environ. Behav., 15 (3), 355-380. CrossRef.

Clements, C. C., A. R. Zoltowski, L. D. Yankowitz, B. E. Yerys, R. T. Schultz, and J. D. Herrington, 2018: Evaluation of the social motivation hypothesis of autism. A systematic review and meta-analysis. JAMA Psychiatry, 75 (8), 797-808. CrossRef.

Cronbach, L. J., 1951: Coefficient alpha and the internal structure of tests. Psychometrika, 16, 297-334. CrossRef.

Eiduson, B. T., 1962: Scientists: Their psychological world. Basic Books. New York, NY, 299 pp.

Evans, G. W., and S. Cohen, 1987: Environmental stress. In D. Stokols and I. Altman (Eds.), Handbook of Environmental Psychology. John Wiley. Hoboken, New Jersey. 1654 pp.

Eysenck, H. J., 1997: Personality and experimental psychology: The unification of psychology and the possibility of a paradigm. J. Pers. Soc. Psychol., 73 (6), 1224-1237. CrossRef.
Feist, G. J., 1998: A meta-analysis of the impact of personality on scientific and artistic creativity. Pers. Soc. Psychol. Rev., 2, 290-309. CrossRef.

2006: The psychology of science and the origins of the scientific mind. Yale University Press, New Haven, CT, 336 pp.

2012: Predicting interest in and attitudes toward science from personality and need for cognition. Personality and Individual Differences, 52 (7), 771-775. CrossRef.

Geddes, L., 2015, December 6: Why do Brits talk about the weather so much? [Available online at https://www.bbc. com/future/article/20151214-why-do-brits-talk-aboutthe-weather-so-much]

Graziano, W. G., M. M. Habashi, and A. Woodcock, 2011: Exploring and measuring differences in person-thing orientations. Pers. Ind. Differ., 51 (1), 28-33. CrossRef.

Hackett, G., N. E. Betz, J. M. Casas, and I. A. Rocha-Singh, 1992: Gender, ethnicity, and social cognitive factors predicting the academic achievement of students in engineering. J. Counseling Psychol., 39 (4), 527-538. CrossRef.

Hyde, J. S., 2014: Gender similarities and differences. Ann. Rev. Psychol., 65 (3), 373-398. CrossRef.

Itti, L, 2007: Visual salience. Scholarpedia, 2 (9), 3327. [Available online at www.scholarpedia.org/article/ Visual salience]

Kidron, R., L. Kaganovskiy, and S. Baron-Cohen, 2018: Empathizing-systemizing cognitive styles: Effects of sex and academic degree. PLoS ONE, 13 (3), 1-17. CrossRef.

Knez, I., 2005: Attachment and identity as related to a place and its perceived climate. J. Environ. Psychol, 25, 207 218. CrossRef.

Knox, J. A., and S. A. Ackerman, 2005: What do introductory meteorology students want to learn? Bull. Amer. Met. Soc., 86, 1431-1435. CrossRef.

, 2008: Recent and future trends in undergraduate meteorology enrollments, degree recipients, and employment opportunities. Bull. Amer. Met. Soc., 89, 873-883. CrossRef.

Kozhevnikov, M., 2007: Cognitive styles in the context of modern psychology: toward an integrated framework of cognitive style. Psychol. Bull., 133 (3), 464-481. CrossRef.

Lawson, J., S. Baron-Cohen, and S. Wheelwright, 2004: Empathising and systemising in adults with and without Asperger Syndrome. J. Autism Dev. Disord., 34, 301310. CrossRef.

Lazo, J. K., M. Lawson, P. H. Larsen, D. W. Waldman, 2011: U.S. economic sensitivity to weather variability. Bull. Amer. Met. Soc., 92, 709-720. CrossRef.

Lent, R. W., F. G. Lopez, and K. J. Bieschke, 1993: Predicting mathematics-related choice and success behaviors: test of an expanded social cognitive model. J. Vocational Behav., 42, 223-236. CrossRef. 
, A. M. Lopez, F. G. Lopez, and H. Sheu, 2008: Social cognitive career theory and the prediction of interests and choice goals in the computing disciplines. $J$. Vocational Behav., 73, 52-62. CrossRef.

, and S. D. Brown, 2006: Integrating person and situation perspectives on work satisfaction: a social-cognitive view. J. Vocational Behav., 69 (2), 236-247. CrossRef.

Levine, T. R., and C. R. Hullett, 2002: Eta squared, partial Eta squared, and misreporting of effect size in communication research. Hum. Comm. Res., 28, 612-625. CrossRef.

Litman, J. A., and C. D. Spielberger, 2003: Measuring epistemic curiosity and its diversive and specific components. J. Pers. Assess., 80, 75-86. CrossRef.

Marcus, A., and I. Oransky, 2012: That sounds familiar. When is using some of the same data acceptable? Lab Times, 4, 35. [Available online at: web.archive.org/ web/20170711182231/http://www.labtimes.org/ labtimes/issues/lt2012/lt04/lt_2012 $04 \quad 35$ 35.pdf

Maddern, C., and D. Jenner, 2009: Public user survey summer 2009. A report of research findings. [Available online at www.wmo.int/pages/prog/amp/pwsp/ documents/Public_User_Survey Report_Summer09 Australia.pdf]

Mass, C. F., 1996: Are we graduating too many atmospheric scientists? Bull. Amer. Met. Soc., 77, 1255-1267. CrossRef.

McNeal, P. M., H. L. Petcovic, N. D. LaDue, and T. D. Ellis, 2019: Identifying significant cognitive factors for practicing and learning meteorology. J. Oper. Meteor., 7 , $1-26$, CrossRef.

Morgan, P., 2010: Towards a developmental theory of place attachment. J. Environ. Psychol., 30 (1), 11-22. CrossRef.

Nettle, D., 2007: Empathizing and systemizing: What are they, and what do they contribute to our understanding of psychological sex differences? Brit. J. Psychol., 98 (2), 237-255. CrossRef.

Pew Research Center, 2008: Where men and women differ in following the news. [Available online at: www. pewresearch.org/2008/02/06/where-men-and-womendiffer-in-following-the-news/]

Phan, M. D., B. E. Montz, S. Curtis, and T. M. Rickenbach, 2018: Weather on the go: an assessment of smartphone mobile weather application use among college students. Bull. Amer. Met. Soc., 99, 2245-2257. CrossRef.

Prediger, D. J., 1982: Dimensions underlying Holland's hexagon: missing link between interests and occupations? Journal of Vocational Behavior, 21 (3), 259-287. CrossRef.

Ritchie, S. J., and Coauthors, 2018: Sex differences in the adult human brain: evidence from 5216 UK Biobank participants. Cereb. Cortex, 28 (8), 2959-2975. CrossRef.

Roe, A., 1952: The Making of a Scientist. Dodd, Mead and Co., New York, NY, 244 pp.
Shteingart, Hanan, T. Neiman, and Y. Loewenstein, 2013: The role of first impression in operant learning. J. Exper. Psychol.: General, 142 (2), 476-488. CrossRef.

Stewart, A. E., 2009: Minding the weather: the measurement of weather salience. Bull. Amer. Met. Soc., 90, 18331841. CrossRef.

, J. K. Lazo, R. E. Morss, and J. L. Demuth, 2012: The relationship of weather salience with the perceptions and uses of weather information in a nationwide sample of the United States. Wea., Clim., Soc., 4, 172-189. CrossRef.

, J. A. Knox, and P. Schneider, 2015: Piloting and evaluating a workshop to teach Georgia teachers about weather science and safety. J. Geoscience Ed., 63 (4), 271-284. CrossRef.

, J. A. Knox, and P. Schneider, 2018: Reaching students and parents through weather science and safety workshops for teachers. Bull. Amer. Met. Soc., 99 (8), 1545-1555. CrossRef.

Stewart, M. E., and E. J. Austin, 2009: The structure of the Autism-Spectrum Quotient (AQ): evidence from a student sample in Scotland. Pers. Ind. Differ., 47 (3), 224-228. CrossRef.

Svedholm-Häkkinen, A. M., and M. Lindeman, 2016: Testing the Empathizing-Systemizing theory in the general population: occupations, vocational interests, grades, hobbies, friendship quality, social intelligence, and sex role identity. Pers. Ind. Differ., 90, 365-370. CrossRef.

Taylor, S. E., S. T. Fiske, 1978: Salience, attention, and attribution: top of the head phenomena. Advances Experimental Soc. Psychol., 11, 249-288. CrossRef.

U.K. Met Office, 2015, August 14: Met Office releases new research looking at the U.K.'s obsession with the weather. [Available online at web.archive.org/ web/20171113060023/https://www.metoffice.gov.uk/ news/releases/2015/weather-research-wow]

Vali, G., and R. Anthes, 2003: "On the Supply of and demand for atmospheric science professionals." Bull. Amer. Met. Soc., 84, 1163-1164. [Available online at: sciencepolicy. colorado.edu/admin/publication_files/Vali_and Anthes - Supply and Demand.pdf]

Wager, E., S. Fiack, C. Graf, A. Robinson, and I. Rowlands, 2009: Science journal editors' views on publication ethics: Results of an international survey. J. Med. Ethics, 35, 348-353. CrossRef.

Wang, X., 2013: Why students choose STEM majors: Motivation, high school learning, and postsecondary context of support. Amer. Ed. Res. J., 50 (5), 1081-1121. CrossRef.

Wheelwright, S., S. Baron-Cohen, N. Goldenfeld, J. Delaney, D. Fine, R. Smith, L. Weil, and A. Wakabayashi, 2006: Predicting Autism Spectrum Quotient (AQ) from the Systemizing Quotient-Revised (SQ-R) and Empathy Quotient (EQ). Brain Res., 1079 (1), 47-56. CrossRef. 
Williams, C. A., P. W. Miller, A. W. Black, and J. A Knox, 2017: Throwing caution to the wind: National Weather Service wind products as perceived by a weather-salient sample. J. Oper. Met., 5, 103-120. CrossRef.

Wilson, G. D., and C. Jackson, 1994: The personality of physicists. Pers. Ind. Differ., 16 (1), 187-189. CrossRef.

Zeyer, A., K. Bölsterli, D. Brovelli, and F. Odermatt, 2012: Brain type or sex differences? A structural equation model of the relation between brain type, sex, and motivation to learn science. Int. J. Sci. Ed., 34, 779-802. CrossRef. 